\title{
Haloperidol produces increased defecation in rats in habituated environments
}

\author{
KRISTANNE H. RUSSELL \\ University of Cincinnati Medical Center, Cincinnati, Ohio \\ STARR H. HAGENMEYER-HOUSER \\ University of Rochester Medical Center, Rochester, New York \\ and \\ PAUL R. SANBERG \\ University of Cincinnati Medical Center, Cincinnati, Ohio
}

\begin{abstract}
For animals placed in novel environments, haloperidol has commonly been shown to decrease defecation. The present study observed the effects of this neuroleptic on defecation of animals in well-habituated environments. After being injected with haloperidol, male Sprague-Dawley rats demonstrated an increase in daytime home cage defecation. This drug-induced defecation was repeatedly observed when rats were tested during the daytime or nighttime in the home cage or in the habituated open field. Significant differences were observed in both fecal weight and fecal boli number. Increased defecation is classically used as an index for animal emotionality. It is possible that the involuntary restriction of locomotion, resulting from haloperidol administration, caused increased levels of emotion in the environmentally habituated animal, thereby increasing defecation. These results may be similar to those described in recent reports of increased anxiety induced by neuroleptics in some humans. Alternatively, this effect could also be due to haloperidol's action on dopamine receptors located centrally within the telencephalon or peripherally within the gastrointestinal tract. Although further studies are required to clarify these possible mechanisms, this is the first report in which a major tranquilizer has been shown to increase animal fecal elimination under certain conditions.
\end{abstract}

Hall (1934) introduced the term emotionality to describe behavioral and peripheral changes that were assumed to be related to elevated sympathetic nervous activity. The increased fecal boli excretion of an animal that is exposed to a novel environment or any hyperarousal situation has been characterized as emotional defecation (Hall, 1934).

Defecation as a measure of emotion has more recently been applied to an array of psychopharmacological studies, including studies of the psychotropic activity and tranquilizing effects of drugs (Allain \& Lechat, 1970; Janssen, Jageneau, \& Schellekens, 1960; Kameyama \& Nabeshima, 1978). These studies demonstrated decreased emotional defecation by animals under the effect of drugs (Allain \& Lechat, 1970; Brimblecombe \& Green, 1962; Cox \& Tye, 1975; Kameyama \& Nabeshima, 1978; Lush, 1975; Nabeshima, Suzuki, \& Kameyama, 1975; Suzuki, Nabeshima, \& Kameyama, 1975). In all of these studies,

This research was supported by a Huntington's Disease Grant from the Pratt Family and Friends, the Hereditary Disease Foundation, the Huntington's Disease Foundation of America, NIMH (MH40127), and a gift from Omnitech Electronics, Inc. (Columbus, $\mathrm{OH}$ ) to $\mathrm{P}$. R. Sanberg. We appreciate the graphic assistance of G. Cohen, L. Chau, and L. Lutton. This research was partially completed at Ohio University, Athens, $\mathrm{OH}$.

Address correspondence to: P. R. Sanberg, Laboratory of Behavioral Neuroscience, Department of Psychiatry, University of Cincinnati Medical Center, Cincinnati, OH 45267. the animals were tested in novel open-field environments. In fact, as described by Kameyama and Nabeshima (1978), "the principle of the test is that the novel situation of the open-field evokes a pattern of behavior characterized by defecation, urination, ambulation, rearing, and grooming in the animals" (p. 675). A typical result of this type of research is a decrease of fecal elimination in animals administered haloperidol (HAL) and then placed in a novel environment (Allain \& Lechat, 1970). The neuroleptic haloperidol is a dopamine receptor antagonist that also induces hypomobility, tonic immobility, or catalepsy in animals (Gelenberg \& Mandel, 1977; Hagenmeyer, Sanberg, Russell, \& Henault, 1985; Sanberg, 1980).

To reduce animals' stress and emotionality and to determine the effects of drugs on defecation in a habituated environment, we undertook the present study to examine the effects of HAL on defecation in various environments and conditions that were not novel to the animal.

\section{METHOD}

\section{Animals and Housing}

Adult male Sprague-Dawley rats, each weighing 400-500 g, were housed individually in stainless steel cages $(24 \times 11 \times 20 \mathrm{~cm})$ and were given free access to food and water. Oxytetracycline was added to the water as a precautionary antibiotic. Twelve-hour light/dark cycles were held constant, starting at 8:00 and 20:00, respectively. 
Apparatus

The open field was a Digiscan Animal Activity Monitor (Omnitech Inc., Columbus, OH), which is described elsewhere (Sanberg, Hagenmeyer, \& Henault, 1985). Each cage contained water and cedar chips and had sides made of clear Plexiglas. The monitors were located in a separate room, and white noise was used to eliminate any auditory influences that may enhance animal emotionality.

\section{Drugs}

Haloperidol (McNeal Pharmaceutical, Ft. Washington, PA) was dissolved in a saline solution that had been adjusted with lactic acid to a $\mathrm{pH}$ of $\mathbf{5 . 0}$ in order to enhance solubility of the drug. Drug solutions were made daily and administered by the same experimenter to minimize variability in animal emotionality induced by handling and injection procedures. Control animals $(0.0 \mathrm{mg} / \mathrm{kg})$ received saline solutions of the same $\mathrm{pH}$.

\section{Procedures}

Home cage study. Thirty-six rats were randomly assigned to one of three daytime treatment groups. At 15:00, each animal was injected intraperitoneally with $0.0,0.1$, or $1.0 \mathrm{mg} / \mathrm{kg} \mathrm{HAL}$ and returned to its home cage. Prior to the injections, the fecal trays were removed, labeled, and replaced. Interruptions into the colony room were minimized by recording fecal boli excretions at 1-h intervals. At the end of the 3-h test period, fecal boli were collected, counted, and weighed for each animal.

An additional 48 rats were injected at 20:00. Drug preparation, dosage, and administration remained constant with procedures described for the daytime groups above. Nocturnal fecal excretions were also collected in the same manner as previously described.

Open-field study. Following a 4-h open-field habituation period two days prior, 12 male rats received $0.0,0.1$, or $1.0 \mathrm{mg} / \mathrm{kg} \mathrm{HAL}$ in a counterbalanced fashion with 3 days between treatments. At 20:00, animals were placed in the Digiscan Animal Activity Monitor where they remained undisturbed for $3 \mathrm{~h}$. Fecal boli were counted and weighed at 23:00. Prior to the drug injection, animals underwent an additional hour of rehabituation in the open-field apparatus at 19:00.

\section{RESULTS}

A $2 \times 3$ ANOVA was used to evaluate the difference between excretions during the daytime and those during the nighttime in the home cage. An ANOVA was also used to analyze the hourly number of fecal boli excretions. Student's $t$ test was used to evaluate the open-field data. Tukey's posttest comparisons were made to evaluate differences between dose groups.

\section{Home Cage Studies}

Figure 1 demonstrates a significant effect of haloperidol in inducing defecation when the drug was administered either nocturnally or during the daytime $[F(2,78)=5.37$, $p<.05]$. A significant main effect of dose was also found for both the daytime and the nighttime $[F(2,33)=4.48$, $p<.05$ and $F(2,45)=3.119, p=.05$, respectively]. A post hoc test showed that defecation during the daytime and the nighttime for the $1.0 \mathrm{mg} / \mathrm{kg}$ group was significantly different from that of the vehicle $(0.0 \mathrm{mg} / \mathrm{kg})$ controls $(p<.05)$. During the nighttime, defecation of the $0.1 \mathrm{mg} / \mathrm{kg}$ group was also significantly different from that of the vehicle control group $(p<.05)$. This difference was not found for these groups during the daytime. The main effect of day versus night on HAL-induced defecation was highly significant $[F(1,78)=33.12$, $p<.001]$. Post hoc comparisons showed that nocturnal defecation was greater than daytime defecation across all doses $(p<.05)$.

Results of counting hourly the number of fecal boli excretions can be seen in Figure 2. A significant main ef-

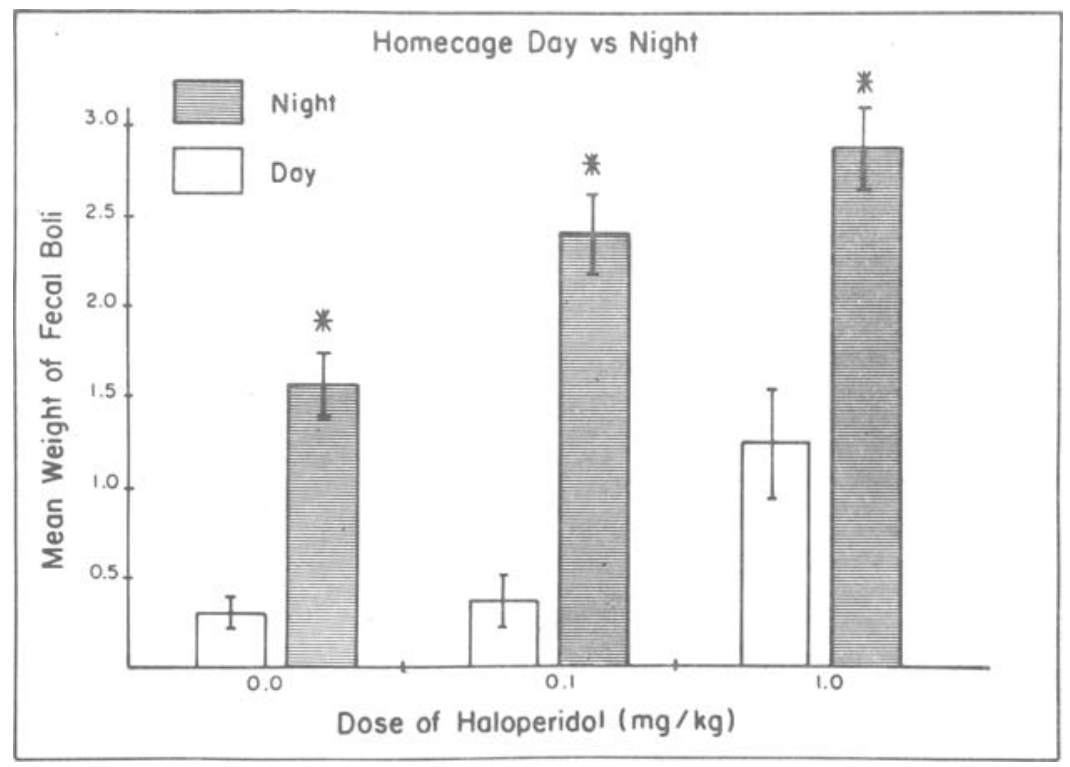

Figure 1. Effects of haloperidol (vehicle [0.0], 0.1 , and $1.0 \mathrm{mg} / \mathrm{kg}$ ) on daytime (15:00-18:00) and nighttime (20:00-23:00) fecal boli weight taken from the home cage. Data represent means $\pm S E M$. The weight of excretions from the $1.0 \mathrm{mg} / \mathrm{kg}$ groups were significantly different from that of the vehicle groups for both daytime and nighttime $(p<.05)$. Defecation of nighttime group was also significantly different from that of the daytime group across all doses. 


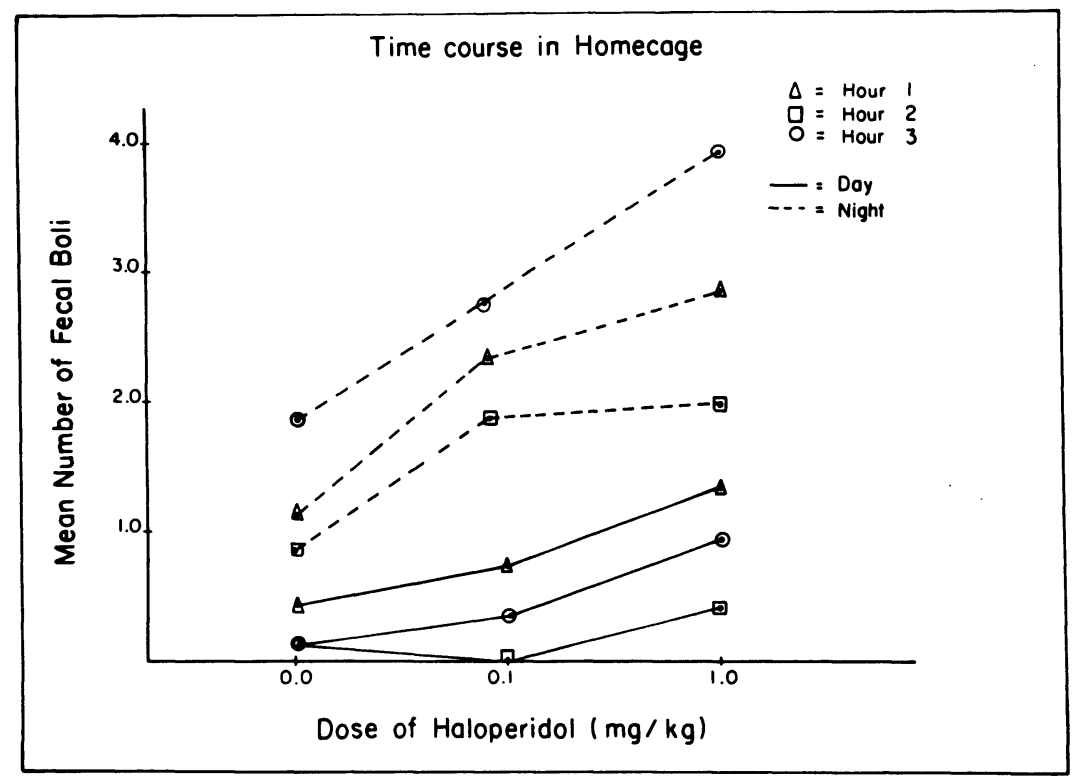

Figure 2. Mean number of 1-, 2-, and 3-h postinjection fecal boli taken from home cages of daytime and nighttime groups. Data represent means $\pm S E M$.

fect of hour was found $[F(2,156)=3.11, p<.05]$ for the daytime and nighttime groups. Post hoc comparisons indicated that the greatest daytime boli excretions occurred during the first hour following injection when compared with excretions during the second hour $(p<.05)$ and the third hour $(p<.05)$; however, at nighttime, the largest number of excretions occurred during the third hour following injection when compared with excretions during the first hour $(p<.05)$ and the second hour $(p<.05)$.

\section{Open-Field Study}

As shown in Figure 3, both fecal boli number and fecal mass were found to be significantly greater in the haloperidol group than in the control group $[t(11)=3.83$, and $t(11)=4.62$, respectively; both $p s<.05$ ] in the habituated open field.

\section{DISCUSSION}

The dopamine receptor antagonist haloperidol, given in specific doses, was found to increase defecation in laboratory rats tested in either the daytime or the nighttime, and in either a habituated open field or in a home cage environment. Used as a major tranquilizer and antipsychotic, haloperidol has been shown to decrease locomotion, rearing, and other aspects of activity in animals (Bernardi \& Neto, 1979; Hagenmeyer, Sanberg, Russell, \& Henault, 1985; Sanberg, 1980). Many of these behavioral effects are mediated by the action of haloperidol on dopamine receptors within the striatum (Sanberg, 1980), which may suggest that haloperidol, in the present study, acted centrally on striatal mechanisms to increase defecation. Such a direct effect may be unlikely, however, since most other investigations have reported reductions in defecation following administration of neuroleptic drugs in emotional animals (Allain \& Lechat, 1970; Brimblecombe \& Green, 1962; Cox \& Tye, 1975; Kameyama, Suzuki, \& Nabeshima, 1980; Lush, 1975; Nabeshima et al., 1975; Suzuki et al., 1975).

Another possible explanation for this drug-induced phenomenon is based on the peripheral effects of haloperidol. As explained by Ormsbee (1984), there is pharmacological evidence that supports the theory

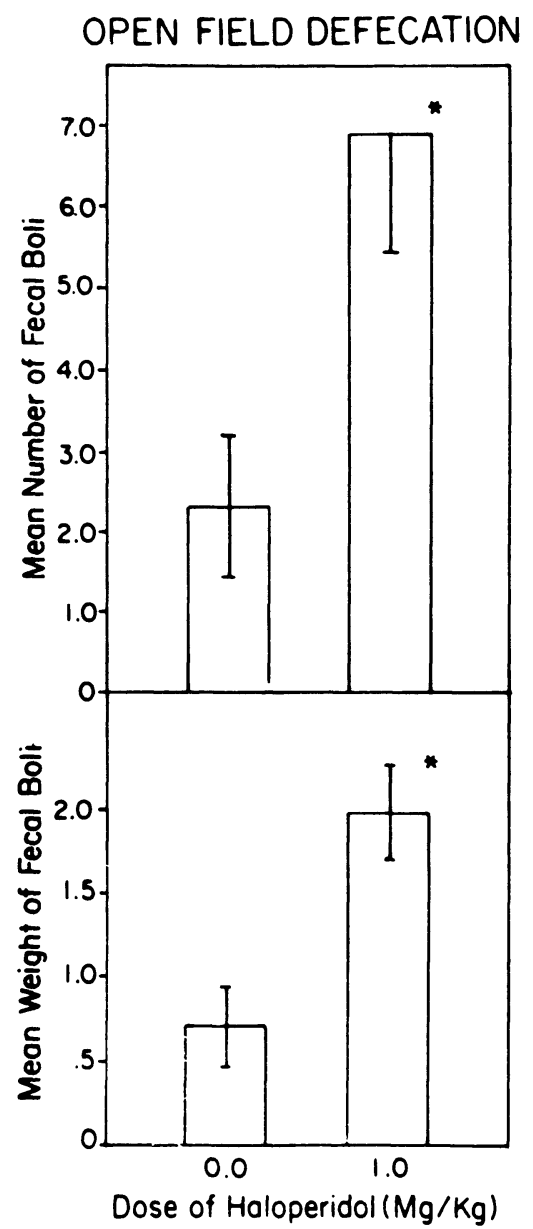

Figure 3. Effects of haloperidol on nocturnal defecation in animals placed in the habituated open field. Data represent means $\pm S E M$ $\left({ }^{*} p<.05\right)$. 
that there are dopamine receptors located in the gastrointestinal (GI) tract (Brogden, Carmine, Heel, Speight, \& Avery, 1982; DeCarle \& Christensen, 1976; Mukhopadhyay \& Weisbrode, 1977; Rattan \& Goyal, 1976; Schulze-Delrieu, 1981). However, the fact that dopamine receptors are not localized in the lower GI tract (Ormsbee, 1984) may argue against this interpretation, since the effects of haloperidol on defecation were seen within a relatively short period after injection in the present study. Also, the fact that haloperidol usually decreases defecation in novel environments (Allain \& Lechat, 1970; Brimblecombe \& Green, 1962; Cox \& Tye, 1975) argues against a peripheral effect.

As demonstrated as early as 1934 (Hall), increased emotionality in animals evokes changes in defecation. It is possible that the present results also reflect enhanced emotionality in haloperidol-treated animals, which thereby increases defecation. This possibility is supported by the fact that the results demonstrated more haloperidol-induced defecation at night than in the daytime. Sanberg, Johnson, Moran, and Coyle (1984) demonstrated that one of the animals' periods of greatest arousal falls between 19:00 and 23:30. Furthermore, defecation in response to haloperidol was also increased in animals in a habituated open-field environment. Taken together, these results support a role for affective states in the mediation of this drug-induced phenomenon. Perhaps the HAL-induced involuntary restriction of locomotor mechanisms in the environmentally habituated animal may increase anxiety levels, thus increasing defecation. It is possible that this effect has similarities to the increased anxiety experienced by some humans who have been given neuroleptics (Linet, 1985; Mikkelsen, Detlor, \& Cohen, 1981).

On the basis of the present study, the possible mechanisms responsible for HAL-induced defecation could be peripheral, central, or affective. Preliminary research from our laboratory has demonstrated that the latter explanation may be correct, since a peripheral neuroleptic, domperidone, failed to produce increased defecation, and the antianxiety agent diazepam was found to attenuate the HAL-induced defecation (Hagenmeyer, Russell, Bunsey, \& Sanberg, 1985). Additional research is needed in order to clarify why a major tranquilizer, such as haloperidol, would cause an increase in animal defecation. Nevertheless, to our knowledge, this is the first report of enhanced defecation following administration of a neuroleptic agent.

\section{REFERENCES}

Allain, P. P., \&echat, P. (1970). Action of psychotropic drugs on emotional defecation in mice. Therapie, 25, 655-662.

BERNARDI, M. M., \& NeTo, J. P. (1979). Effects of abrupt and gradual withdrawal from long-term haloperidol treatment on open field behavior in rats. Psychopharmacology, 65, 247-250.

Brimblecombe, R. W., \& GreEN, A. L. (1962). Effect of monoamine oxydase inhibitors on the behavior of rats in Hall's open field. Nature, 194, 983.

Brogden, R. N., Carmine, A. A., Heel, R. C., Speight, T. M., * AVERY, G. S. (1982). Domperidone: A review of its pharmacological activity, pharmacokinetics and therapeutic efficacy in the symptomatic treatment of chronic dyspepsia and as an antiemetic. Drugs, 24, $360-400$.

CoX, T., \& TYE, N. (1975). The effects of amphetamine, imipramine and ICI 58, 834 (vivalan), a potential antidepressant, on unconditioned behavior in rats. Psychopharmacologia, 40, 297-304.

DeCarle, D. J., \& Christensen, J. (1976). A dopamine receptor in esophageal smooth muscle of the opossum. Gastroenterology, 70, 216-219.

Gelenberg, A. J., \& MANDel, M.R. (1977). Catatonic reactions to high-potency neuroleptic drugs. Archives of General Psychiatry, 34, 947-950.

Hagenmeyer, S. H., Russell, K. H., Bunsey, M. D., \& Sanberg, P. R. (1985). Haloperidol-induced defecation in laboratory rats: Peripheral or emotional effect. Society for Neuroscience Abstracts, 11, 1192.

Hagenmeyer, S. H., Sanberg, P. R., Russell, K. H., \& Henault, M. A. (1985). Haloperidol produces decreased activity and increased defecation in rats. Eastern Psychological Association Abstract, 56, 58.

HALL, C. S. (1934). Emotional behaviors in the rat: I. Defecation and urination as measures of individual differences in emotionality. Journal of Comparative Psychology, 18, 385-403.

Janssen, P. A. J., Jageneau, A. H. M., \& Schellekens, K. H. L. (1960). Chemistry and pharmacology of compounds related to 4(4-hydroxy-4-phenyl-piperidino)-butyrophenone: Part IV. Influence of haloperidol (R 1625) and chlorpromazine on the behavior of rats in an unfamiliar "open-field" situation. Psychopharmacologia, 1, 389-392.

Kameyama, T., \& Nabeshima, T. (1978). Effects of 1,3-diphenyl-5(2-demethylaminopropionamide)-pyrazole[difenamizole] on a conditioned avoidance response. Neuropharmacology, 17, 249-256.

Kameyama, T., SuzUKi, M., Nabeshima, T. (1980). Effects of 5 hydroxytryptamine on defecation in open field behavior in rats. Pharmacology, Biochemistry \& Behavior, 12, 875-882.

LineT, L. S. (1985). Tourette syndrome, pimozide, and school phobia: The neuroleptic separation anxiety syndrome. American Journal of Psychiatry, 142, 613-615.

LUSH, I. E. (1975). A comparison of the effects of mescaline on activity and emotional defecation in seven strains of mice. British Journal of Pharmacology, 55, 133-139.

Mikkelsen, E. J., Detlor, J., \& Cohen, D. J. (1981). School avoidance and social phobia triggered by haloperidol in patients with Tourette's disorder. American Journal of Psychiatry, 138, 1572-1575.

MuKhopadHYAY, A. K., \& WeisBrode, N. (1977). Effects of dopamine on esophageal motor function. American Journal of Physiology, 232, E19-E24.

NAbeshima, T., SUZUKI, M., \& Kameyama, T. (1975). Studies on biogenic amines and behavior: II. Relationship between emotionality and defecation. Japanese Journal of Pharmacology, 25 (Suppl. 48).

OrmSBEe, H. S. III (1984). Dopamine agonist/antagonists in the treatment of gastrointestinal diseases. In G. P. Poste, S. T. Crooke (Eds.), Dopamine receptor agonists (pp. 333-353). New York: Plenum Press.

Rattan, S., \& Goyal, R. K. (1976). Effects of dopamine on the esophageal smooth muscle invivo. Gastroenterology, 70, 377-381.

SANBERG, P. R. (1980). Haloperidol-induced catalepsy is mediated by postsynaptic dopamine receptors. Nature, 284, 472-473.

Sanberg, P. R., Hagenmeyer, S. H., \&e Hault, M. A. (1985). Automated measurement of multivariate locomotor behavior in rodents. Neurobehavioral Toxicology \& Teratology, 7, 87-94.

Sanberg, P. R., Johnson, D. A., Moran, T. H., Coyle, J. T. (1984). Investigating locomotion abnormalities in animal models of extrapyramidal disorders: A commentary. Physiological Psychology, $12,48-50$.

Schulze-Delrieu, K. (1981). Metoclopramide. New England Journal of Medicine, 305, 28-33.

Suzukı, M. T., Nabeshima, T., \& Kameyama, T. (1975). Studies on biogenic amines and behavior: I. Relationship between brain monoamines and defecation in rats. Japanese Journal of Pharmacology, $25,47-48$.

(Manuscript received for publication August 28, 1986.) 